\title{
Correction: FGFR1 $\beta$ is a driver isoform of FGFR1 alternative splicing in breast cancer cells
}

\author{
Ming Zhao ${ }^{1}$, Ming-Lei Zhuo ${ }^{2}$, Xiaofeng Zheng ${ }^{3}, X^{\prime}$ iaoping Su$^{3}$ and Funda Meric- \\ Bernstam ${ }^{1,4,5}$ \\ ${ }^{1}$ Department of Investigational Cancer Therapeutics, The University of Texas MD Anderson Cancer Center, Houston, TX, USA \\ ${ }^{2}$ Key Laboratory of Carcinogenesis and Translational Research, Department of Thoracic Medical Oncology-I, Peking University \\ Cancer Hospital and Institute, Beijing, China \\ ${ }^{3}$ Department of Bioinformatics and Computational Biology, The University of Texas MD Anderson Cancer Center, Houston, \\ TX, USA \\ ${ }^{4}$ Department of Breast Surgical Oncology, The University of Texas MD Anderson Cancer Center, Houston, TX, USA \\ ${ }^{5}$ Institute of Personalized Cancer Therapy, The University of Texas MD Anderson Cancer Center, Houston, TX, USA
}

Published: December 10, 2019

Copyright: Zhao et al. This is an open-access article distributed under the terms of the Creative Commons Attribution License 3.0 (CC BY 3.0), which permits unrestricted use, distribution, and reproduction in any medium, provided the original author and source are credited.

This article has been corrected: Due to errors during image assembly, the beta-actin control in Figure 6D was accidentally flipped. The corrected Figure 6D is shown below. The authors declare that these corrections do not change the results or conclusions of this paper.

Original article: Oncotarget. 2019; 10:30-44. https://doi.org/10.18632/oncotarget.26530 


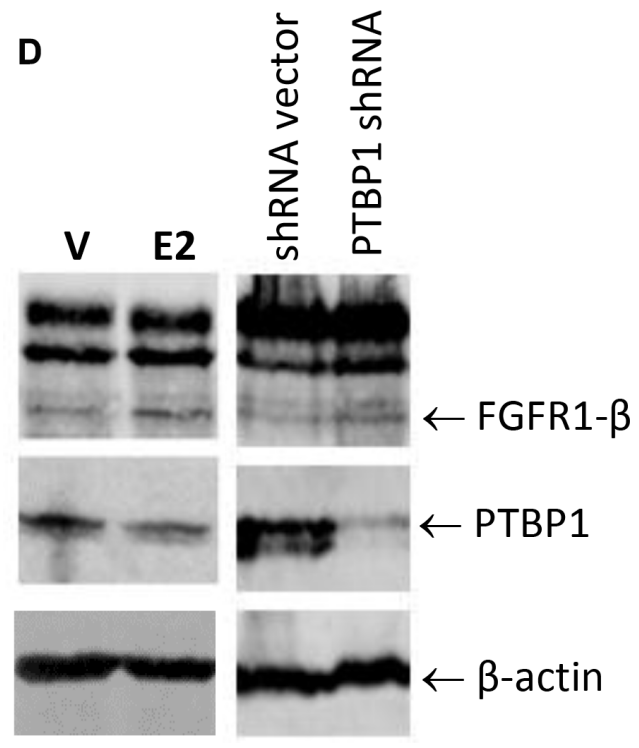

Figure 6: Estrogen regulation of FGFR1 splicing in breast cancer cells. (A) RT-PCR of FGFR1 $\alpha$ and FGFR1 $\beta$. MDA-MB-134VI cells were cultured for 3 days with hormone-deprived FBS, then treated with $17 \beta$-estradiol at $0.1 \mu \mathrm{M}(\mathrm{E}), 4$-hydroxytamoxifen at $1 \mu \mathrm{M}(\mathrm{T})$, or both (E+T), or vehicle (V) for 2 days. RT-PCR was performed to detect mRNAs of FGFR1 $\alpha$, FGFR1 $\beta$, and GAPDH. (B) Immunoblotting. The MDA-MB-134VI cells cultured with hormone-deprived FBS or normal FBS for 3 days were incubated with 17 $\beta$-estradiol or 4-hydroxytamoxifen treatment respectively for 2 days. E1 and E2: $17 \beta$-estradiol at 0.1 and $0.5 \mu \mathrm{M}$; T1 and T2: 4-hydroxytamoxifen at 1 and $5 \mu \mathrm{M}$; V: vehicle. (C) Ratio of quantitated FGFR1 $\beta / F G F R 1 \alpha$ expression in Figure 6B. (D) WB of FGFR1 and PTBP1. MDA-MB$134 \mathrm{VI}$ cells were treated with $17 \beta$-estradiol (E2) at $0.1 \mu \mathrm{M}$ or vehicle control for 2 days, or infected with PTBP1 shRNA virus or control shRNA. Expression of FGFR1 and PTBP1 were detected with anti-FGFR1 and anti-PTBP1 antibodies. (E) Effects of drug combination on cell survival. MDA-MB-134VI cells seeded in 96-well plates were incubated with single or combination of 4-hydroxytamoxifen and BGJ-398 at doses from 0.05-20000nM and 1250-20000nM respectively for 5 days. Cell survival rate was measured by SRB assay. IC50 and combination index (CI) were calculated using CompuSyn software. $(\mathrm{CI}<1$ : synergy; $\mathrm{CI}>1$ : antagonism) (F) Colony formation assay, MDA-MB-134VI cells were cultured in the presence of BGJ-398 and 4-OHT at $1 \mathrm{nM}$ and $0.1 \mathrm{nM}$ respectively and their combination for 4 weeks. Colony formation was visualized by crystal violet staining. Total colony area was quantitated using ImageJ. 